\title{
Community Health Centers in US Inner Cities: From Cultural Competency to Community Competency
}

\author{
James Jennings, PhD \\ Urban and Environmental Policy and Planning, Tufts University
}

\begin{abstract}
This paper critiques the idea of multiculturalism in the delivery of public health to lowincome and communities of color as incomplete and limited. Health activists, and very importantly, community health centers in these places must become more involved with struggles against structural inequalities. Using the theory of social determinants of health, it is proposed that the leadership of community health centers consider how spatial inequalities impact directly on the particular health needs of low-income groups and people of color. Until public health addresses inequality, higher rates of ill health and health disparities will continue to plague economically distressed urban neighborhoods in the US. Based on an earlier study for the Robert Wood Johnson Foundation, including a literature review and interviews with key informants, the author argues that public health is a key venue for the empowerment of inner city neighborhoods. Therefore, community health centers should be perceived and supported as community actors involved directly or indirectly with a range of economic and political issues, rather than simply the place - albeit quite multicultural - where poor and working-class people go when they are sick.
\end{abstract}

\section{Introduction}

This essay proposes that the idea of multiculturalism or cultural diversity in the delivery of health services is limited and incomplete in responding to health challenges in US lowincome urban communities. In these places, where problems of poverty, unemployment, bad housing, toxic air, and dirty streets are found in greater levels than other places, community health centers must move beyond simply being culturally sensitive or reflective of local groups. Rather, they must enhance their organizational role as community actors and become involved in working with other non-health organizations seeking to challenge the local and spatial manifestations of inequality. The rationale for this claim is founded in the theory of social determinants of health where structural inequality is considered an impediment to good health and wellness. Within this framework public health officials interested in enhancing the well-being of residents in low-income and impoverished neighborhoods must be familiar with discourses and strategies which reduce wealth and power inequalities. Community health centers in low-income communities represent a key venue for linking better health for all people with a more just society.

Community health centers in US urban centers were originally founded as 'community' organizations with broad social and economic missions, as well as the delivery of public health. ${ }^{(1)}$ These federally-funded organizations play a special role in the provision of health care to low-income commuinties and people of color in the US. According to the National Association of Community Health Centers, Inc.:

Minorities are disproportionately represented among health center patients. Of the over 15 million patients currently relying on health centers, 9.6 million are people of color..... Hispanic/Latinos make up the largest minority group at $35 \%$ of all health center patients and African Americans make up nearly a quarter of all patients. ${ }^{(2)}$ 
Two of the first community health centers in the post-WWII period, in Boston, Massachusetts and Mound Bayou, Mississippi, were founded with missions that went beyond, simply, the issue of health as illness or disease. As noted by Taylor:

The history of federal involvement with today's community health centers is integrally tied to the Johnson administration's War on Poverty and the civil rights movement. Initially named neighborhood health centers, these clinics were created in 1965 as part of the Office of Economic Opportunity (OEO) to provide health and social services access points in poor and medically underserved communities and to promote community empowerment..... (3)

Community health centers were thus envisioned as essentially community institutions that would be an integral part of a neighborhood's social, economic, and institutional infrastructure; they would play the role of agents seeking to politically empower residents as a way to improve living conditions, and thereby reduce ill-health.

This kind of mission for the delivery of public health in economically-distressed urban areas has generally been abandoned, for the most part. As Bonnie Lefkowitz writes:

Today's debates on the public's health are overwhelmed by a preoccupation with genomic advances and market innovations. In contrast, the early centers had a common sense, holistic philosophy that came from understanding that good health is close to impossible if you have to choose among food, rent, and medicine. ${ }^{(4)}$

The last several decades have witnessed greater specialization in the kind of activities defined as public health and government funding streams have narrowed the potential scope of this sector. In spite of this development, community health centers in low-income neighborhoods still face a challenge of delivering quality health services to populations that are impoverished and living in places characterized by high levels of poverty and economic distress. Reports show consistently that people living in these places - in many cases, people of color - tend to have higher incidents of ill-health. One idea for responding to this situation is ensuring that the delivery of health services is racially/ethnically/culturally sensitive to the receiving groups.

\section{Theory of Social Determinants of Public Health}

In recent years a 'new' paradigm for achieving quality health for all has emerged in the international arena. Described as the 'social determinants' school, its focus is understanding associations between social and economic inequalities and a range of health problems in poor and low-income communities. As explained by Wilkinson and Marmot:

Health policy was once thought to be about little more than the provision and funding of medical care: the social determinants of health were discussed only among academics. This is now changing. While medical care can prolong survival and improve prognosis after some serious diseases, more important for the health of the population as a whole are the social and economic conditions that make people ill and in need of medical care in the first place. Nevertheless, universal access to medical care is clearly one of the social determinants of health. ${ }^{(5)}$

A recent report published by the Centers for Disease Control in Atlanta, Georgia concludes that :

social determinants of health life-enhancing resources, such as food supply, housing, 
economic and social relationships, transportation, education, and health care, whose distribution across populations effectively determines length and quality of life. ${ }^{(6)}$

According to social determinants theory, non-health factors like the economic or political characteristics of neighborhoods, and generally racial and ethnic inequality, can be the causes of bad health and therefore should be addressed under public health strategies. Therefore, community health centers - more so than big hospitals - can probably play a more effective role in improving living and health conditions in that they immediately confront the consequences of institutional, economic, and political causes of bad health.

A study supported by the Robert Wood Johnson Foundation identified a few organizations across the country that are building and providing community-based health approaches to vulnerable populations within this kind of context. In these handful of cases health centers are reaching out to work with non-health partners, and on non-health issues. In Addressing Health Disparities In Community Settings: An Analysis of Best Practices in CommunityBased Approaches to Ending Disparities in Health Care the authors suggest that successful programs approach their patients, not as individual consumers but rather an integral part of a community, and thus they are not only serving patients, but providing communitybuilding services. ${ }^{(7)}$ According to this view health is approached as an integral part of social, economic, and political frameworks and relationships that define the community.

One leading writer in this area, Dennis Raphael, observes that:

There is increasing interest in the role that community structures play in promoting health and well-being among citizens.....These community structures may involve local services; the presence of affordable housing, healthy food, and public transportation; community activities that support quality of life; or the sense of social cohesion that exists among community members. Attention is also being paid to how political decisionmaking supports or hinders the establishment and maintenance of these health-enhancing community structures. ${ }^{(8)}$

Another prominent scholar, Vicente Navarro, defends this idea in The Political and Social Contexts of Health. His team of contributors provide concrete examples of how health problems are directly connected to political and economic decisions, and inequality, in some countries. ${ }^{(9)}$

Alas, this is not a new or isolated call. In 1990 Frances Baum, Director of the Southern Community Health Services Research Unit at Flinders Medical Centre in South Australia, proposed a 'new public health' which is 'predicated on the belief that threats to the health of the public are not confined to disease and lifestyle risk.....they also emanate from social organization and structures' and '.....threats to health are not confined to direct causes of illness but extend to the structures at the heart of society. New public health workers should be prepared to challenge these. ${ }^{\prime(10)}$

Broadly speaking, this means that the leadership and staff of community health centers in US impoverished and low-income neighborhoods should approach a neighborhood's social and economic distress as relevant in responding to the health problems that clients bring to the center. In fact, a number of initiatives reflecting this approach have been founded across the country as described in a report, Promoting Health Equity: A Resource to Help Communities Address Social Determinants of Health. ${ }^{(11)}$ It also presents (nine) case studies of initiatives across the US as a basis for showing how individual organizations pursue 
implementation of social determinants theory in attempts to improve the health status of residents in low-income and impoverished areas.

\section{Limitations of Multiculturalism}

In order to make health services more responsive to people of color, some scholars and health officials encouraged that this sector adopt and operate within a framework of what can be referred to as cultural competency. This can be defined as the capacity to understand and acknowledge cultural and racial differences between those delivering public health services and those who receive such services. The providers of health, in other words, should be able to communicate and utilize the cultural resources that are part of groups being served in inner cities and impoverished communities to advance health goals.

While this idea is not contradictory with the social determinants school described above, it has the capacity to obscure the importance of focusing on structural inequalities in poor communities. It can serve to sustain hierarchical relationships of power between public health bureaucracies and impoverished groups needing health services. While cultural competence can be attained by providing professional development and training to the providers of health services so that they become more cognizant and sensitive to racial and ethnic differences, it does fail to challenge the distribution of wealth or power in local neighborhoods. Yet the latter, in a sense, can represent the independent variables, which impact on the quality of health.

The idea of community competency is more conceptually aligned with social determinants of health. This suggests a situation where the community health center is recognized and accepted as a key participant and leader in community struggles seeking to address issues of economic, educational, or political inequalities for the residents of a community. The difference in cultural competency is the focus on social change. Cultural competency can be designed and implemented in ways that reflect appreciation of 'multiculturalism', but say little about the attainment of equality at the local level, in other words. There is an acknowledgement in the former term that public health issues in low-income and impoverished communities are strongly associated with inequality and, thus, the issue of health betterment has to be tackled within a context of also challenging political, economic, and educational inequality.

According to the Bureau of Health Professions and the Basic Area Health Education Center, cultural competence strategies focus on racial and ethnic changes associated with specific populations rather than community-wide level changes; recruiting health professionals from different racial and ethnic backgrounds, including encouraging young people of color to pursue health careers. Here, attention is paid to ensuring accessibility of health services to vulnerable populations and communities of color. This approach is emphasized in Section 330 of the Public Health Service Act as amended by the Health Centers Consolidation Act of 1996 (P.L. 104-229) where it stipulates three ideas: first race and ethnicity have to be considered within a broad context that includes other variables such as 'language, gender, socio-economic status, sexual orientation, physical and mental capacity, age, religion, housing status, and regional differences.' A second idea is that cultural competency is a significant proposition as a factor in ensuring quality health care. A third idea is that health centers should seek participation from the 'diverse cultures in their communities' and 'hire culturally and linguistically appropriate staff.'(12) 
more proactive, rather than reactive stance. For example, the conclusion of Cohen, Gabriel and Terrell is a key point regarding the importance of a diverse workforce:

......at least four practical reasons can be put forth for attaining greater diversity in the health care workforce: (1) advancing cultural competency, (2) increasing access to high quality health care services, (3) strengthening the medical research agenda, and (4) ensuring optimal management of the health care system. ${ }^{(13)}$

However, this important observation still places the community health center in a sort of 'receiving' end of demographic and community changes. It places the community health center in a conceptually stationary position regarding a distressed social and economic context.

Interestingly, and in spite of the critique just offered, cultural competence should be a critical aspect of the delivery of quality health care in low-income and urban communities. Yet, according to some observers, training for the benefit of medical and public health workers is not widely accepted. One study found that cross-cultural training is lacking and not substantive for residents in training in medical professions. Based on focus groups and interviews with 68 residents across the nation it was reported that at some medical schools:

Residents in this study reported receiving mixed messages about cross-cultural care. They were told it is important, yet they received little formal training and did not have time to treat diverse patients in a culturally sensitive manner. As a result, many developed coping behaviors rather than skills based on formally taught best practices. ${ }^{(14)}$

It seems that although achieving cultural competency is but a piece of the evolving formula for enhancing the effectiveness of health services delivered to consumers in communities characterized by high levels of poverty, the idea is still resisted. This suggests that the issue of resistance to confronting ill health for impoverished and working-class within the school of social determinants is huge. But this is more the reason we should consider community health centers in US inner cities as vanguard spaces for pushing social determinants of health as an approach to improving local health conditions.

\section{Community Health Centers as Community Organizations}

In its seminal report, Unequal Treatment: Confronting Racial and Ethnic Disparities in Health Care (2002) the Institute of Medicine offers strategies aimed at responding to and reducing racial and ethnic health disparities. The recommendations generally touched upon:

.....increasing the awareness of racial and ethnic health disparities among general public, providers, and key stakeholders; increasing the presence of racial and ethnic minorities as health professionals; enhancing patient-provider communication (translation, community health workers); increasing preventive care; implementing patient education; collecting data about health care by race, ethnicity, economic level, language; using measures of racial and ethnic disparities in performance evaluation; using sub-group classifications within broad racial and ethnic categories; and conducting research on ethical issues and other barriers to eliminating disparities. ${ }^{(15)}$

These suggestions still place relatively little emphasis on how economic class and spatial inequality, as played out in neighborhood settings, affects the quality of health or strategies for improving such. 
A community health center can be doing an excellent job in making available a range of health services, but if it does not have 'penetration' in the community, the impact of such services can be limited as noted by one researcher. Terence Giovanni interviewed 223 carers of Latino children in the city of San Francisco. As concluded in Barriers to Primary Care Among Latino Children in a Low Income Urban Community, the research indicates strongly that community health centers are effective in enhancing access for medically underserved groups and communities. ${ }^{(16)}$ The report concludes that 'low penetration' in low-income communities can inhibit this potential role for community health centers. If low penetration is associated with a degree of organizational or institutional 'distance' from community issues, then it is a problem given the potential impact these organizations can have on the quality of health in a neighborhood.

Bailus Walker, et al. are specific about these kinds of relationships and profer that public health leaders should work in greater communication and collaboration with those engaged in local economic development. They write:

Racial/ethnic health status disparities intersect with the economy in numerous places including the distribution of income and other resources. The relationship between disease, specifically infectious disease, and economic development has been of increasing interest to scholars and practitioners in a number of fields. ${ }^{(17)}$

For example, the number and concentration of commercial outlets in a neighborhood with high density rates is a potential health issue. A relationship between commercial outlets and neighborhood health outcomes, including mortality, for example, was reported in a study byYen and Kaplan. The authors showed that the concentration of commercial outlets over a period of time could be quite detrimental to residents. ${ }^{(18)}$

Researcher Arline T. Geronimus explains that this approach places some emphasis on the evaluation of non-health social policies, like welfare reform, and its impact on the state of health, or accessibility to good health resources. She writes:

In a structural framework, policies that affect the context of urban poverty - such as the distribution of wealth, the built environment, segregation, and access to technologies, information or other resources - influence fundamental causes of health inequality. So, too, do policies that affect the integrity of the autonomous institutions-formal organizations, informal networks, ideologies, and cultural frameworks - that members of oppressed groups work to develop and maintain to mitigate, resist, or undo the structural constraints they face. ${ }^{(19)}$

Public health advocates should have familiarity not just with a community's consumers but also with the discourses and events, and networks, associated with comprehensive community-building strategies, including community and economic development.

E. Richard Brown utilizes a case study to focus on the Tenderloin Senior Outreach Project in San Francisco. He argues that community action, community organization, and community development are key components for influencing local public policy for health promotion. He writes:

.....health promotion programs usually focus on getting individuals to change their personal health-related behaviors and seldom broaden their objectives to empowering people beyond arenas of their individual lifestyles or to changing environmental factors 
that shape behavior and influence health status. ${ }^{(20)}$

Another researcher argues similarly that community empowerment strategies:

......can combat a generalized susceptibility to disease from powerlessness, it then becomes critical for health educators to embrace empowerment education programs. In brief, an empowerment education approach would always engage people through a group dialogue process in identifying their problems; in crucially assessing the social, historical, and cultural roots of their problems; and in developing action strategies to change their personal and social lives. ${ }^{(21)}$

The delivery of public health in low-income communities, in other words, should be framed within a context of community development and empowerment, one that has the potential to elevate the political and economic influence of residents. Supporting this proposal, Richard Hofrichter writes:

Public health must function as an expression of the community, as its representative seeking to advocate for social change that transforms the conditions that cause ill health. The issue demands political will, speaking out and building partnerships with those in need, and recognizing limited resources within rigid mandates in a conservative climate. Collaboration with and support of the community means an ongoing process of relationship building, dialogue, and cooperative action to address community health needs and issues, based on trust and reciprocity. ${ }^{(22)}$

This implies that local health centers should be working actively with community groups to expand the social and economic resources and capacities of the neighborhood.

There are hosts of community participants who can help resolve or mitigate against the effects of negative neighborhood characteristics and developments, and thereby indirectly improve the wellbeing of residents. For example, owners of micro-enterprises, or small businesses, can pursue their commercial interests in ways that contribute to health problems of residents; religious leaders can influence how some residents approach health issues; and public schools can be engaged in important informational campaigns aimed at improving the health consciousness of children, youth and families. Community actors are reciprocally impacted by racial and ethnic changes and neighborhood conditions such as low income status, immigration, unemployment, low labor force participation, poor schooling, environmental and transportation inequality, and other challenges.

Diagram 1 illustrates the kinds of relationships proposed in this paper. ${ }^{(23)}$ It suggests that while multiculturalism can be a basis for delivery of culturally-sensitive health services to residents in low-income neighborhoods, it can be disconnected from community actors involved with alleviating or reducing a range of social and economic distresses on residents. The concept of community competency helps to reduce this disconnection.

\section{Conclusion}

The nurturing of a stronger and more effective presence in neighborhoods as a community player can be a difficult process for community health centers. Roussos and Fawcett observe that:

Partnerships working in communities with concentrated poverty face several unique barriers. Economic problems, such as high unemployment or inadequate housing, 


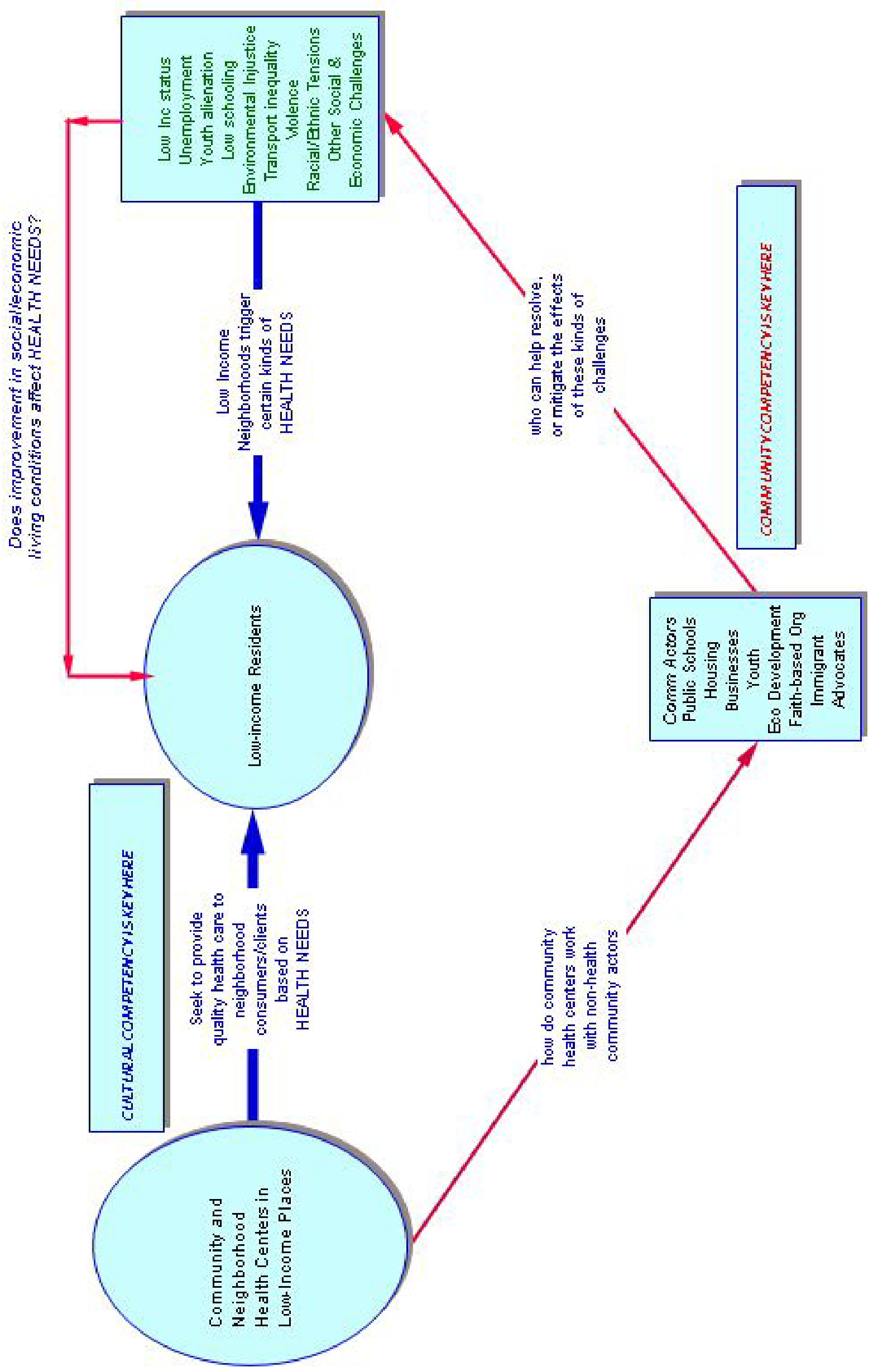


often overshadow the categorical health concerns, such as substance abuse or childhood immunizations, to be addressed by a partnership. Although social and economic problems are likely to be interconnected with health concerns, the community may not have sufficient resources to allocate to multiple and interrelated issues.....Competition for scarce resources and economic and social gaps between low-income residents and those with financial resources may further challenge collaborative and substantial investments in local work. ${ }^{(24)}$

A range of organizational activities would be affected by the seeking of greater community role and presence. These include legal and financial issues, organizational and business regulations, governance, board and personnel issues, federal health regulations, space needs, financial health regulations, quality assurance regarding health services including clinical, oral, pharmaceutical, and emergency services. Additionally, government policies and categorical funding streams generally do not support broad community interventions on the part of local health centers, or activities that are outside traditional health activities.

It is here where foundations could play a particularly important role. They can support innovations aimed at integrating public health and community development. Resources and sustained support would be required for planning and technical assistance to community health centers seeking to build bridges with non-health partners. Such investment could contribute to the discovery and dissemination about emerging best practices regarding this kind of organizational role. Professional development of staff is an area that also would require continual attention and resources. Foundations can also play a major part in the evaluation of innovations pursued by community health centers. Documenting and assessing the relationships between the manifestations of structural inequalities at the local level, and better health could assist in changing how the American public fundamentally thinks about health. The challenge is daunting, but this paper proposes that community health centers are on the frontlines of understanding the association of social and economic inequalities and ill health. They should be allowed the space to explore such associations in responsible ways if it means that a community's wellness can be improved. Public health, as a tool, for challenging inequality may result in much broader and longer-lasting benefits making public health more than merely the place people go to when they are sick.

\section{Acknowledgement}

The author wishes to acknowledge that financial support for research for this article was provided by the Robert Wood Johnson Foundation's New Connections Program and the additional support of its dedicated leadership and staff. The article would probably not have been initiated or completed without the support of this Program. Acknowledgements are also extended to Ms. Lisa Roland Labiosa and Ms. Briane C. Knight for reading and assisting with earlier versions of this article.

\section{References}

1. Jason Corburn, 'Reconnecting With Our Roots: American Urban Planning in the Twenty-First Century', Urban Affairs Review, 42:5 (2007), 688-713.

2. 'Community health centers' (CHCs) in this paper means 'federally qualified health centers' as defined by the US federal government's Health Resources and Services Administration, the Bureau of Primary Health Care, and the Center for Medicare and Medicaid Services in Washington D.C. CHCs are generally located in high need areas across the US. They provide comprehensive services and are open to anyone needing such services. The services delivered are monitored by appropriate government agencies for purposes of accountability and safety. In 2002 there were 
about 3,500 such centers in the US.

See: http://www.aapcho.org/site/aapcho/content.php?type=1\&id=9707.

3. J. Taylor, 'The Fundamentals of Community Health Centers', National Health Policy Forum (August 31, 2004), 3.

4. B. Lefkowitz, Community Health Centers: A Movement and the People Who Made it Happen (New Jersey: Rutgers University Press, 2007). See also M. Boutilier, S. Cleverly, and R. Labonte, 'Community as a Setting for Health Promotion' in B. D. Poland, L. W. Green, and, I. Rootman (eds.), Settings for Health Promotion: Linking Theory and Practice (California: Sage Publications, Inc., 99).

5. Richard G. Wilkinson, and Michael Marmot, The Social Determinants of Health: The Solid Facts (Denmark: World Health Organization, 2003), 7.

6. Laura K. Brennan Ramirez, E. A. Baker, and M. Metzler, Promoting Health Equity: A Resource to Help Communities Address Social Determinants of Health (Atlanta: US Department of Health and Human Services and Centers for Disease Control and Prevention, 2008), 6.

7. B. Siegel, H. Berliner, A. Adams, and D. Wasongarz, Addressing Health Disparities in Community Settings: An Analysis of Best Practices in Community-based Approaches to Ending Disparities in Health Care (New York: Robert Wood Johnson Foundation, 2003), 1.

8. D. Raphael, R. Renwick, I. Brown, et al., 'Community Quality of Life in Low-income Neighborhoods: Findings from Two Contrasting Communities in Toronto, Canada', Journal of the Community Development Society, 32:2, (2001), 311. See also R. Dennis, Social Determinants of Health: Canadian Perspectives (Toronto: Canadian Scholarly Press, 2004).

9. V. Navarro, The Political and Social Contexts of Health (New York: Baywood Publishing Company, 2004).

10. F.E. Baum, 'The New Public Health: Force for Change or Reaction?', Health Promotion International, 5:2 (1990), 149.

11. Ibid., 12.

12. Marilyn H. Gaston, Policy Information Notice: Health Center Program Expectations, Bureau of Primary Health Care (August 17, 1998), 2, 9, and 11.

13. J. J. Cohen, B. A. Gabriel, and C. Terrell, 'The Case for Diversity in the Health Care Workforce', Health Affairs, 21:5 (September/October 2002), 90-102.

14. H. L. Park, 'Enabling Services at Health Centers: Eliminating Disparities and Improving Quality', (New York: The New York Academy of Medicine, September 29, 2005).

15. B. D. Smedley, A. Y. Stith, and A. R. Nelson, Unequal Treatment: Confronting Racial and Ethnic Disparities in Health Care Committee on Understanding and Eliminating Racial and Ethnic Disparities in Health Care (Washington, DC: The National Academies Press, 2002).

16. T. Giovannini, 'Barriers to Primary Care Among Latino Children in a Low Income Community', Abstract, Book Assoc Health Services Res Meeting 15 (1998), 26-7.

17. B. Walker, V. M. Mays, and R. Warren, 'The Changing Landscape for the Elimination of Racial/ Ethnic Health Status Disparities', Journal of Health Care for the Poor and Underserved, 15:4 (November 2004), 506-521. 
18. I. H. Yen, and G. A. Kaplan, 'Neighborhood Social Environment and Risk of Death: Multilevel Evidence from the Alameda County Study', American Journal of Epidemiology, 149:10 (May 15, 1999), 898,898-907.

19. A. T. Geronimus, 'Addressing Structural Influences on the Health of Urban Populations', in R. Hofrichter (ed.), Health and Social Justice: Politics, Ideology and Inequality in the Distribution of Disease (San Francisco, CA: John Wiley \& Sons, Inc., 2003).

20. E. R. Brown, 'Community Action for Health Promotion: A Strategy to Empower Individuals and Communities', International Journal of Health Services, 21:3 (1991), 441-456.

21. N. Wallerstein, 'Powerlessness, Empowerment and Health: Implications for Health Promotion Programs', American Journal of Health Promotions, 6:3 (January/February 1992), 198.

22. R. Hofrichter, 'The Politics of Health Inequities: Contested Terrain', in R. Hofrichter (ed.), Health and Social Justice: Politics, Ideology and Inequality in the Distribution of Disease (San Francisco, CA: John Wiley \& Sons, Inc.; 2003), 43.

23. Others use similar charts to explain linkages between policy, inequality, and health. See 'Figure 1.1: Pathways from Social Determinants to Health' in Promoting Health Equity, op. cit., p. 10. See also N. Freudenberg, et al., Cities and the Health of the Public (Nashville, Tennessee: Vanderbilt University Press, 2006), chapter 2.

24. S. T. Roussos, and S. B. Fawcett, 'A Review of Collaborative Partnerships as a Strategy for Improving Community Health', American Review of Public Health 21 (May 2000), 389. 